\title{
Begräbnisdichtung im russischen Barock: Simeon Polockijs Threnodien
}

https://doi.org/10.1515/slaw-2021-0002

Summary: This article is about Simeon Polotskii's voluminous lament of 1669 about the death of Mariia Il'inichna, the wife of tsar Aleksei Mikhailovich. The lament is analysed as a specimen of baroque court poetry and as a poetic cycle. Special attention is paid to its religious content. What are the lament's principal ideas about death and the afterlife? How does it treat the central motif of contemptus mundi, the Christian contempt of life on earth? And how does it relate to the religious tenets of the Orthodox Church?

Keywords: Funeral poetry, poetic cycle, baroque, contemptus mundi, eastern and western Christendom

Zur Erinnerung an

Konrad Onasch (1916-2007)

\section{Einleitung}

Marija Il’inična, die Gattin des Zaren Aleksej Michajlovič, starb am 3. März 1669 im Kindbett. Simeon Polockij hat seine Threnodien zu diesem Anlass geschrieben und dem Witwer zugeeignet ${ }^{1}$. Das war eines jener handschriftlichen „Büchlein“

1 Die Rechtschreibung der Überschrift ist ebenso unregelmäßig wie die des gesamten Textes. Außer den offiziellen Titeln des Zaren enthält sie auch eine Aufzählung der zu erwartenden Einzeltexte: Френы, или плачи / всех санов и чинов православнороссийского / царства о смерти / Благоверныя и Христолюбивыя Государыни / Царицы и Великия Княгини / Марии Иличны. / Ту же утешения различных добродетелей / ко всем саном и чином. / По сих епитафиа, или надгробия / и / Слово последняго целования от гроба / к оставшим. / Напоследок емлимата и их толкования, / стихами краесногласными равномерне / сложеная. / И / Благочестивейшему Тишайшему Богом / венчанному Великому Государю Царю / и Великому Князю Алексию Михайловичю / Всеа Великия и Малыя и Белыя Росии / Самодержиу

*Kontaktperson: Prof. Dr. em. Joachim Klein, Universität Leiden, Niederlande, E-Mail: j.h.klein6@mac.com 
(knižicy), mit denen er als Hofdichter zeremonielle Anlässe zu würdigen pflegte, und für die er eine Belohnung erwarten konnte ${ }^{2}$. Aus der umfangreichen Überschrift erfährt man, dass Simeon die Threnodien dem Zaren persönlich überreichen durfte. Dieses Geschenkexemplar ist nicht überliefert. Wir kennen das Werk daher nur als Teil einer späteren Sammelhandschrift, des Rifmologion. Als Simeon 1680 starb, war seine redaktionelle Arbeit an den Threnodien noch nicht ganz abgeschlossen ${ }^{3}$.

In diesem Werk lobt Simeon die Tugenden und Verdienste der Verstorbenen, er würdigt den Kummer der Hinterbliebenen und tröstet sie. Damit erfüllt er die drei Aufgaben, die ein Begräbnisdichter seit der Antike zu bewältigen hatte laudatio, lamentatio und consolatio (vgl. Esteve-Forriol 1962, Krummacher 1974, Wiegand 1997; zur Totenklage in der Literatur der orthodoxen Slaven vgl. Burkhart 1997). Gegenstand der vorliegenden Arbeit sind die Threnodien als Werk der höfischen Gelegenheitsdichtung. Es geht um ihre Eigenart als literarischer Zyklus $^{4}$ und die Nähe zum Barock. Besondere Aufmerksamkeit gilt dem religiösen Gehalt des Werks. Welche Auffassung von Tod und Jenseits liegt ihm zugrunde? Was ist vom zentralen Motiv des contemptus mundi zu halten? Und wie steht es mit dem Verhältnis der Threnodien zu den Glaubenswahrheiten der Ostkirche?

\section{Ein literarischer Zyklus}

Ebenso wie die übrigen knižicy Simeons waren die Threnodien nicht nur ein Werk der Dichtung, sondern kraft ihrer graphischen Gestaltung auch der bildenden Kunst: Mit dem quasi-architektonischen Aufbau der Textblöcke wollen sie nicht nur gelesen, sondern auch betrachtet werden - so wie man ein Gebäude oder ein Bild betrachtet ${ }^{5}$. Die Handschrift, die Simeon dem Zaren überreichte, war vermutlich reich geschmückt ${ }^{6}$ - nicht nur ein Medium schriftlicher Kommunikation, son-

\footnotetext{
врученая. / В лето от создания мира 7177, от / рождества Христова 1669 априлия 20 день (Polockij 2017: 261; eingeklammerte Seitenangaben beziehen sich im Folgenden auf diese Ausgabe).

2 Vgl. Tatarskij 1886: 209-210, mit dem Zitat der entsprechenden Bittschrift. Grebenjuk (1982: 301) nennt Simeon den „ersten professionellen Dichter“ der russischen Literatur.

3 Zur Textgeschichte vgl.: Eremin 1953: 242, Grebenjuk 1982: 292, und vor allem Sazonova 2017: XI-XIV.

4 Zum Begriff des literarischen Zyklus vgl. Vroon 2001: 155-156.

5 Vgl. Eremin 1966: 212-217. Meine Formulierung geht auf diese Arbeit zurück. Zum visuellen Aspekt des Werks vgl. auch Strätling 2005: 383-407, und Sazonova 2013: CXXXV-CXLIII.

6 Von Simeons Geschenkexemplaren ist nur das ältere „Büchlein“ Orel rossijskij überliefert (Der russische Adler, 1667). Das war eine Handschrift von 57 Blättern „im Quartformat mit Goldschnitt“,
} 
dern auch ein dekorativer Gegenstand, der dem Prunk der höfischen Umgebung entsprach.

Im Folgenden beschränke ich mich auf den literarischen Aspekt der Threnodien. Ihre zyklische Geschlossenheit verdanken sie nicht nur dem einheitlichen Bezug auf den traurigen Anlass; als umfangreiches und reich gegliedertes Ganzes vergegenwärtigen sie auch, wie noch zu zeigen sein wird, die Vielfalt der Trauergemeinde. Die Überschrift beginnt mit diesen Worten: Threnodien, oder Klage aller Ränge und Stände des rechtgläubig-russischen Reichs [...] (S. 261). Zu dieser Trauergemeinde gehören außer dem Zaren auch dessen Söhne und Töchter, ferner die politischen Berater, die Streitkräfte, die Klöster, die Stadtbewohner, die Armen und andere.

\section{Komposition; die lyrischen Sprecher}

In der Handschrift hatte die Überschrift der Threnodien die architektonische Form eines weitgespannten Bogens (Eremin 1966: 214). Es folgt eine längere Widmung in Prosa; als Autor zeichnet mit einer Demutsformel der „vielfach sündige Mönchspriester Simeon Polockij “7. Das war offenbar der Text einer Rede, die Simeon beim Überreichen seines Werks gehalten hat ${ }^{8}$ (man wüsste gerne etwas mehr über dieses Ritual). Die Verstexte, die nun folgen, bestehen zunächst aus 24 Klage- und Trostgedichten. Auf sie antwortet die verstorbene Zarin mit einem Abschieds-,,Wort“, einem „letzten Kuss“, ebenfalls in Versen: „Slovo poslednjago celovanija“.

Eine buntscheckige Reihe von Texten schließt sich an: barocke Figurengedichte, Epitaphe und nicht weniger als neun Embleme. Aus der Sicht der vorliegenden Arbeit sind diese Texte virtuoses Beiwerk und stehen somit außerhalb des literarischen Zyklus - jenes kompositorischen Ganzen, das sich aus den Klage- und Trostgedichten einerseits und der Replik der verstorbenen Zarin andererseits zusammensetzt. Der Umfang der Klage- und Trostgedichte schwankt je-

„mit farbigen Zeichnungen illustriert“ und in „himbeerrote Seide“ gebunden (Grebenjuk 1982: 288). In der mir vorliegenden Druckfassung fehlen fast alle graphischen Schmuckelemente. Sie hätten diese Ausgabe wohl allzu sehr verteuert.

7 „Многогрешный иерономах Симеон Полоцкий“ (S. 263). Hier und im Folgenden stammen die Übersetzungen aus dem Russischen von mir.

8 Eine solche Rede hat Simeon bei der Überreichung seines „Büchleins“ auf die Geburt des Thronfolgers Simeon Alekseevič im Jahre 1665 gehalten; so auch bei der Überreichung eines weiteren „Büchleins“ auf die Ernennung des Aleksej Alekseevič zum Thronfolger im Jahre 1667 (Tatarskij 1886: 78, 124). 
weils zwischen 42 und 144 Versen; das Abschiedswort der Zarin enthält sogar 290 Verse $^{9}$.

Der Versrhythmus der Threnodien beruht auf der Syllabik des russischen Barock, so wie sie von Simeon begründet worden war. Die einzelnen Texte bestehen durchweg aus Elfsilblern mit einer Zäsur nach der fünften Silbe und mit weiblichem Paarreim. Ihrerseits bilden die 24 Gedichte, die dem Abschiedswort der Zarin vorausgehen, zwölf Zweiergruppen, deren Glieder durch die Überschriften jeweils als „Klage“ („Plač““) und als „Tröstung“ („Utešenie“) ausgewiesen sind; in den Überschriften der „Klagen“ hat Simeon diese Zweiergruppen von 1 bis 12 durchnummeriert ${ }^{10}$.

In den Klage- und Trostgedichten der Threnodien ist es nicht etwa Simeon, der als lyrischer Sprecher auftritt, sondern jeweils eine andere Instanz, die von Gedicht zu Gedicht wechselt. Wer diese lyrischen Sprecher sind, erfahren wir aus den Überschriften. In der ersten „Klage“ ist das zum Beispiel der Zar, in der sechsten sind das „alle heiligen Klöster“. Die Sprecher der Trostgedichte sind keine Personen oder Institutionen, sondern Allegorien; sie verkörpern christliche Tugenden wie den Glauben, die Hoffnung oder die Liebe. Das erinnert an die Poetik des barocken Schuldramas, wie es auch in Russland gepflegt wurde ${ }^{11}$; man kann vermuten, dass die Threnodien nicht nur zur Lektüre, sondern auch zum Vortrag bestimmt waren, aber wohl nicht zur szenischen Aufführung, wie etwa die Begrüßungsverse, mit denen Simeon im Jahre 1656 zu Beginn des Schwedischen Krieges den Einzug des Zaren in Polock gefeiert und damit zum ersten Mal dessen Aufmerksamkeit auf sich gezogen hatte (Tatarskij 1886: 48). Wer hätte in diesem Fall die Rolle des Zaren Aleksej Michajlovič übernehmen sollen?

In den Threnodien zeigt sich der „rhetorische Grundzug“ der Barocklyrik. Die Rhetorik lehrt, „wie über einen beliebigen Gegenstand ,füglich und artig“ gesprochen werden kann“ (vgl. Müller 1957: 205; Müller 1929: 83, vgl. auch Sazonova 2006: 113-117). Es war Simeons Aufgabe, dem traurigen Anlass nach Maßgabe der rhetorischen Vorschriften, der höfischen Etikette und der herrschenden Moral gerecht zu werden. Den lyrischen Sprechern liegt es daher fern, sich individuellen

9 In der Druckvorlage ist dieser lange Text in Abschnitte unterteilt, bei jeweils neu ansetzender Nummerierung der Verse. Der Bequemlichkeit halber verwende ich beim Zitieren für dieses Werk eine durchlaufende Nummerierung der Verse.

10 Auf diese Gedichte beziehen sich im Folgenden die eingeklammerten Nummern mit je einem Buchstaben: Die erste „Totenklage“ wird also mit '(1a)' bezeichnet, die entsprechende „Tröstung“ mit '(1b)' usw. Die von mir verwendete Nummer 13 bezieht sich auf das Abschiedswort der Zarin, z.B.: (13, V. 5-290).

11 Simeon war auch Autor von zwei Schuldramen (Eremin 1953: 248-256). Zur Allegorik des Barock vgl. Alt 1995: 35-348. 
Gefühlsregungen zu überlassen. Sie beschränken sich vielmehr auf Trauerformeln wie das unvermeidliche „Schluchzen“ und die reichlich fließenden „Tränenströme“; eine Ausnahme bildet allenfalls die „Klage“ der Zarensöhne (2a), wie wir noch sehen werden.

Simeons Sprecher bringen, mit anderen Worten, nur diejenigen Gefühle und Gedanken zum Ausdruck, die man am Hof des Zaren Aleksej Michajlovič zum gegebenen Anlass erwarten musste. Zeremonielle Gelegenheitsdichtung ist immer auch „Gesellschaftsdichtung“, sie bringt Überpersönliches zum Ausdruck und befriedigt so ein ,gesellschaftliches Repräsentationsbedürfnis“ (vgl. van Ingen 1966: 50; Segebrecht 1977: 58). Vor allem hatte Simeon zu beachten, dass sein zarischer Adressat sehr fromm war, was ihm als Mönch natürlich nicht schwer fiel $^{12}$; der Beichtvater des jungen Aleksej Michajlovič war einer von jenen „Eiferern der Frömmigkeit“ (,revniteli blagočestija“) und „Gottliebenden“ („,bogoljubcy“), zu denen auch Avvakum gehörte (Zen'kovskij 1970: 102-103).

Simeons Sprecher pflegen eine gehobene Ausdrucksweise: Sie verwenden Verse, geizen nicht mit sprachlichem Zierrat und halten sich an das Kirchenslavische; dies freilich in dessen hybrider Variante ${ }^{13}$, wohl aus Gründen der Verständlichkeit. Sie benutzen auch gerne die Gelegenheit zu theologischer Reflexion und moralischer Belehrung. Als Autor der Threnodien ist Simeon daher nicht nur Dichter, sondern auch Prediger. Zum Beispiel handelt ein großer Teil der ersten „Klage“ von der biblischen Heilsgeschichte; man gewinnt so den Eindruck, als spreche hier eigentlich nicht der Zar, sondern der hochgelehrte Priestermönch Simeon. Mutatis mutandis gilt das auch für andere „Klagen“ oder „Tröstungen“; in solchen Fällen ist die Rolle des lyrischen Sprechers kaum mehr als eine Maske. Mit Blick auf den lehrhaft-repräsentativen Charakters der Barockpoetik wurde dies jedoch kaum als Problem empfunden.

In der ersten „Klage“ ergreift der Zar die Sprecherrolle mit dem Gewicht seiner herrscherlichen Autorität; ebenso wie am Anfang des gesamten Werks werden auch in der Überschrift dieser „Klage“ die Titel aufgezählt (S. 264). Dem Zaren folgen seine Söhne ${ }^{14}$ (2a) und Töchter (3a). Danach kommen staatliche Institutionen zu Wort, wie der „geistliche Stand“ (4a) und der „Ältestenrat” (,sigklit“, 5a). Hiermit ist wohl die Bojarenduma gemeint, vielleicht aber auch die „nahe Duma“ („bližnjaja duma“), ein kleineres Beratungsgremium (Torke 1986b: 160). Es folgen

12 Zur Frömmigkeit des Zaren vgl. Zen'kovskij 1970: 102, und Longworth 1984: pass.

13 Zum „hybriden“ Kirchenslavisch vgl. Živov 1996: 26, 31 et pass. Leider gibt es noch keine Untersuchung von Simeons Sprache.

14 Der Titel lautet: „Die zweite Klage der erlauchten Schar der Zarensöhne“ - „Плачь вторый Пресветлаго лика чад Царских“ (2a). Dabei ist zu beachten, dass das kirchenslavische Wort „čado“ nicht nur ‘Kind', sondern auch ‘Sohn' bedeuten kann (D’jačenko 1899: 808). 
„alle Klöster“ (6a), „die gesamte rechtgläubige Streitmacht“ (7a) und ,alle Städte des frommen großrussischen Reiches“ (8a).

Hiernach sind die „Fremden und Zugewanderten“ an der Reihe (9a). Die allegorische Sprecherin des entsprechenden Trostgedichts ist die „Fremdenliebe“ „strannoljubie“ (9b). Im Domostroj, dem weltlich-religiösen Verhaltenslehrbuch des Alten Russland, findet man eine Parallele zu diesem Gedicht. Dort ermahnt ein Vater seinen Sohn, Ortsfremde gastfreundlich aufzunehmen ${ }^{15}$. Das war eine der moralischen Normen, die Simeon bei Hofe voraussetzen konnte. Im Übrigen ist anzunehmen, dass er bei den „Fremden und Zugereisten“ speziell auch an diejenigen Mönche dachte, die im Zuge der Nikonschen Kirchenreform ebenso wie er selber aus den westlichen Randgebieten des Reiches nach Moskau gekommen und deshalb ebenfalls der „Fremdenliebe“ bedürftig waren.

Am untersten Ende der sozialen Stufenleiter melden sich „alle Bettler, Witwen und Waisen" zu Wort (10a). Bemerkenswerterweise fehlt in Simeons Trauergemeinde die Landbevölkerung mit den meist leibeigenen Bauern. Die Bettler und Waisen konnten als Empfänger christlicher Barmherzigkeit erwähnt werden. Davon konnte bei den steuerpflichtigen Bauern jedoch keine Rede sein - als zumeist analphabetisches 'Volk' kamen sie als Mitglied der Trauergemeinde nicht in Betrach ${ }^{16}$. Im Weiteren tritt als Sprecherin der „Klagen“ das „rechtgläubige russische Reich" in Erscheinung, womit Simeon den gesamtstaatlichen Charakter der Trauergemeinde hervorhebt (11a); auch hätte er ohne das Einschieben dieses Sprechers nicht die biblische Zwölfzahl der Totenklagen erreicht. In der exponierten Schlussposition folgt die orthodoxe Kirche, und zwar in zwiefacher Rolle: in der Totenklage als ecclesia militans („ratujuščaja cerkov““, 12a) und im dazugehörigen Trostgedicht als ecclesia triumphans („,cerkov’ toržestvujuščaja“, 12b).

Wie wir gesehen haben, tritt das Zarenhaus zu Beginn der „Klagen“ dreifach als Sprecher in Erscheinung (1a, 2a, 3a). Drei Auftritte hat in den „Klagen“ auch die Kirche, allerdings nicht in unmittelbarer Aufeinanderfolge: als „geistlicher Stand“ (4a), als die Gesamtheit der Klöster (6a) und als die ecclesia militans (12a). In der Übereinstimmung der Dreizahl scheint sich das byzantinische Prinzip der 'Symphonie' von Monarchie und Kirche anzudeuten. Allerdings hat die russische Kirche, wie schon erwähnt, im letzten Trostgedicht als ecclesia triumphans noch einen weiteren Auftritt; offenbar wollte der Priestermönch Simeon ihr besondere Geltung verschaffen. Dies freilich bei gebotener Anerkennung des herrscherlichen Primats, wie es sich in der Vorrangstellung des Zaren am Anfang der Toten-

15 „Poslanie i nakazanie oto otca k synu“ - „Sendschreiben und Belehrung des Vaters für seinen Sohn“, in: Domostroj 1990: 104-109, hier 105. Übereinstimmungen dieser Art findet man auch an anderen Stellen der Threnodien.

16 Vgl. Pančenko 1973: 188-189, über Simeons Verachtung des ‘unwissenden’ Volkes. 
klagen und der Wiederholung seiner Herrschertitulatur ausdrückt; in der Moskauer Synode von 1666-1667 war dieser Primat eigens bekräftigt worden (Torke 1986a: 117); an ihr hatte Simeon eifrig mitgewirkt (Tatarskij 1886: 80; Majkov 1889: 23-39).

Soweit die Sprecher der „Klagen“. Was die Sprecher der „Tröstungen“ betrifft, so handelt es sich, wie schon gesagt, um Allegorien, die jeweils eine christliche Tugend verkörpern. Eine Ausnahme bildet hier nur die letzte „Tröstung“, als deren Sprecherin die ecclesia triumphans auftritt. In den übrigen „Tröstungen“ sprechen „der Glaube“ (1b), „die Hoffnung“ (2b), „die Liebe“ (3b) und „die Frömmigkeit“ (4b). Zur moralischen Belehrung der Trauergemeinde spenden diese Tugenden sich selber reiches Lob, was dann zum Lob der verstorbenen Zarin überleitet. Als Ausbund der genannten Tugenden wird der Zarin die ewige Seligkeit zuteil. Hierin liegt der Trost, den Simeon der Trauergemeinde spendet: Stets aufs Neue ermahnt er sie, ihre Tränen zu trocknen und sich über die Aufnahme der Zarin ins Himmelreich zu freuen. Die allegorische Liebe wendet sich mit den folgenden Worten an die Hinterbliebenen: Die Zarin ,jauchzt nun bei Jesus, / und herrscht mit einer unvergänglichen Krone. / Ihr sollt sie daher / in solcher Herrlichkeit begrüßen, und nicht unter Tränen schluchzen. / Haltet also inne mit eurer allzu großen Klage, / es gibt keinen Grund zum Weinen, es gibt einen Grund zur Freude“"17.

$\mathrm{Zu}$ den allegorischen Sprechern der Trostgedichte gehört als Tugend des Ältestenrats auch „die Weisheit“ (5b) und als Tugend der Klöster „die Enthaltsamkeit“ (6b). Ferner spricht „der Friede“ (7b), „die Fürbitte“ (8b), die schon bekannte „Fremdenliebe“ (9b) und jene „Barmherzigkeit“, die man den Witwen, Waisen und Bettlern schuldet (10b). Hierauf melden sich zusammenfassend ,alle Tugenden“ $\mathrm{zu}$ Wort (11b), womit dann durch die ecclesia triumphans (12b) wieder die biblische Zwölfzahl erreicht wird.

Auch hier sind einige Erläuterungen angebracht. Mit der „Fürbitte“ ist jene Vermittlung gemeint, die man als gläubiger Christ seitens der Hinterbliebenen und der Heiligen nach dem Tode für das eigene Seelenheil erhoffen konnte. Bei Simeon und insgesamt auch in der Ostkirche ist die Grenze zwischen Tod und Leben keineswegs undurchdringlich: Lebende und Tote gehören $\mathrm{zu}$ ein und derselben Gemeinde der Gläubigen ${ }^{18}$. Als Mitglieder dieser Gemeinde können und sollen die Lebenden Einfluss auf das weitere Schicksal der Verstorbenen neh-

17 „С Ним [Исусом] же в совете ныне ликовствует, / в венце нетленном ныне царствует. / Должни вы убо ей приветствовати / толика царства, не слезно ридати. / Лишите убо плачь сей ваш превелий, / несть вины плача, есть вина веселий“ (3b, 47-52).

18 Vgl.: Onasch 1962: 247; Bulgakov [1965]: 382; Benz 1971: 44, spricht von einer „mystischen Gemeinschaft". 
men: Sie beten für sie, lassen auch, was bei Simeon nicht eigens zur Sprache kommt, Messen feiern, und sie spenden Almosen ${ }^{19}$. In dem Trostgedicht, das die allegorische Enthaltsamkeit an die Klöster richtet, liest man daher: „Eure Gebete zu Gott sind nicht vergeblich, / sie stiften übergroßen Nutzen für die [verstorbene] Zarin“20.

In ihrem Abschiedswort bittet Marija Il'inična ihren Gatten nicht nur um Fürbitte, sondern auch um Vergebung für die Kränkungen, die sie ihm jemals angetan haben mochte (13, V. 89-94). Mit derselben Bitte wendet sie sich an die übrigen Adressaten: Sie sollen ihr verzeihen, für sie beten und ihr so zur ewigen Seligkeit verhelfen. Das entsprach einem frommen Brauchtum (Košeleva 2000); bei Simeon dient es auch der Funeralpanegyrik: Die Zarin, die an anderer Stelle geradezu als Heilige dargestellt wird (s.u.), übt sich mit ihrer Demut in einer christlichen Kardinaltugend - ebenso wie der „vielfach sündige Mönchspriester Simeon Polockij“ als Autor des einleitenden Prosatextes.

In dem Trostgedicht, das zur Totenklage der Streitkräfte gehört, ist es nicht etwa die Tapferkeit oder der Gehorsam, die hier als allegorische Sprecher auftreten, sondern der „Friede“ und damit auch die Friedensliebe. Christus wird gleich zu Anfang als „Friedensherrscher“ („Car’ mira“ - 7b, V. 1) gerühmt, die verstorbene Zarin als „Förderin des gegenwärtigen Friedens“ - „nastojaščago mira promyslnica“ (7b, V. 50). Allerdings liegt es der Zarin fern, den Krieg von 1754-1767 gegen die polnisch-litauische Rzeczpospolita zu verurteilen. Dieser Krieg war ein Jahr vor ihrem Tod auf eine für Russland überaus günstige Weise beendet worden - mit der Annexion der linksufrigen Ukraine, des rechtsufrigen Kiev und großer Teile Weißrusslands. Diesem Stand der Dinge entspricht in der Überschrift der Threnodien und der ersten Totenklage die Titulatur des Zaren als „Selbstherrscher des gesamten Groß-Russland, von Kleinrussland und von Weißrussland“ (S. 261, 264) $)^{21}$.

Wie man hinzufügen kann, zeigt diese Stelle, dass die Zarinnen der Moskauer Rus' bei weitem nicht immer so passiv und zurückgezogen waren, wie das bei der gängigen Vorstellung des altrussischen terem nahezuliegen scheint (vgl. Thyrêt 2001). Eine Anspielung auf die politische Tätigkeit der Zarin liegt schon in der Wendung von der Zarin als „Förderin des gegenwärtigen Friedens”. In der ersten

19 Vgl. Košeleva 2000 über die Testamente der Moskauer Oberschicht im 17. Jahrhundert. Das Totengedenken ist auch dem westlichen Christentum nicht fremd, hat aber für die Orthodoxie als Bestandteil der Liturgie wohl eine größere Bedeutung; vgl. Bulgakov [1965]: 382. Vgl. zum orthodoxen Totengedenken auch Dergačeva 2003, und das Stichwort „Pominovenie usopšich“ in: Slovar' 1992 II: Sp. 1842-1843.

20 „Не всуе ваши молитвы у Бога, / полза бе ними Царици премнога“ (6b, V. 63-64).

21 Vgl. zu dieser Titulatur Robinson 1974: 32. 
„Klage“, als deren Sprecher der Zar auftritt, lobt er sie denn auch als „Säule“ des Reiches - diese Metapher erscheint hier drei Mal, jeweils am Anfang eines Verses - und als seine tatkräftige „Helferin“ in „Beratungen und beim Regieren“; das Wort „Hilfe“ („pomošč'“) erscheint vierfach, und zwar wiederum am Anfang der entsprechenden Verse (1a, 55-70).

Im Trostgedicht des allegorischen Friedens wird der Krieg nicht an sich verurteilt. Aber man darf nur einen gerechten Krieg führen, wie das im Feldzug gegen die Rzeczpospolita der Fall war, als der wahre Glaube gegen den Katholizismus verteidigt wurde. Unter solchen Umständen ist das Kämpfen „ein heiliger Dienst“ („svjata služba“ - 7b, V. 17); die Zarin wird dafür gepriesen, dass sie die russischen Soldaten mit ihren Gebeten begleitet, das Heer mit reichen Belohnungen angespornt und dessen Leistungen mit dienstlichem Aufstieg honoriert habe $(7 a$, V. 75-78) 22 .

Einer Erläuterung bedarf schließlich auch die zwiefach allegorische Gestalt, in der die russische Kirche am Ende der Totenklagen und der Trostgedichte auftritt - als ecclesia militans und als ecclesia triumphans ${ }^{23}$. Die Kirche ist eine Zweieinheit: Als irdische Kirche verkörpert sie die Gemeinschaft der lebenden Christen und als himmlische die Gemeinschaft der Christen im Jenseits. Auf Erden muss die Kirche kämpfen und leiden, im Himmel hat sie als „Braut des Bräutigams Christi“24 teil an der ewigen Seligkeit und kann so wiederum als Fürsprecherin zugunsten der Hinterbliebenen wirken.

Bei Simeon hat der Kampf der ecclesia militans auch eine aktuelle Bedeutung. Er bezieht sich auf die Kirchenspaltung, die durch die Nikonschen Reformen verursacht wurde, und damit auch auf die Verfolgung der altgläubigen 'Ketzer'. An diesem Glaubenskampf hatte Simeon in der Moskauer Synode von 1666-1667 auf Seite der offiziellen Kirche mit großem Eifer mitgefochten (Tatarskij 1886: 79-87). Mit der Bildsprache, die er in diesem Zusammenhang verwendet, kommt eine allegorische Schriftauslegung ins Spiel ${ }^{25}$. Es geht um die mit zwölf Sternen gekrönte und „in die Sonne gekleidete“ Frauengestalt der Johannesapokalypse. Sie bringt einen Sohn zur Welt, den ihr ein „schwarzer Drache“ vergeblich zu entreißen ver-

22 „Не всуе болезнь и труды бываху, / прещедрую бо мзду воспринимаху. / Кто верно служил, от нея взыскася, / от менша чина в вящший подвизася“ - „Krankheit und Mühen waren nicht vergeblich. / Wer brav diente, sich bittend an sie [dieZarin] wandte, / wurde von einem geringen Rang in einen höheren befördert“" (7a, V. 75-78).

23 Vgl. das Stichwort „Cerkov’ nebesnaja i zemnaja“ in: Slovar’ II, 1992: Sp. 2337-2338.

24 Die verstorbene Zarin wendet sich mit den folgenden Worten an die Kirche: „Oh, du gesamte hochheilige östliche Kirche / geliebte Braut des Bräutigam Christus“ - „Вся восточная церкви пресвятая, / Христу Жениху невесто любая [...]“ (13, V. 271-272).

25 Zur allegorischen Schriftauslegung bei Simeon vgl. Pančenko 1973: 183-184, 187. 
sucht (12a, V. 10: „zmij chermnyj“). Bei Simeon steht diese Frau für die ecclesia militans, der kleine Sohn steht für die Gläubigen. Was den Drachen betrifft, so verkörpert er die altgläubige 'Irrlehre', vor der die Gläubigen durch die Kirche gerettet wurden (Simeon konnte nicht ahnen, dass die Altgläubigen zu dieser Zeit erst am Anfang ihrer langen Geschichte standen). Auf die Kirchenspaltung verweist im selben Gedicht auch der alttestamentarische Absalom, der sich gegen seinen Vater, den König David, erhob und dabei sein Leben verlor (12a, V. 3334) - auch dies ein Beispiel für Simeons allegorische Textauslegung.

\section{Das christliche Weltbild}

In Simeons Zyklus dominiert die Sichtweise eines frommen Christen, der sich an andere Christen wendet. Es geht um die ewige Seligkeit und die Art und Weise, wie diese zu erlangen sei. Seit dem Sündenfall gliedert sich die Welt in zwei Teile: in ein zeitliches Diesseits und ein zeitloses Jenseits. Die Zeit ist gleichbedeutend mit Vergänglichkeit und Tod; das entspricht dem traditionellen Bild des mit einer Sense bewaffneten Chronos. Von Zeit und Tod ist in den Threnodien sehr viel die Rede. Simeon verwendet dabei eine Bildsprache, die man aus der westlichen Barockdichtung kennt. In der Totenklage des Russischen Reiches findet sich zum Beispiel die folgende „Bildreihe“ ${ }^{\text {(26: }}$

Der Mensch ähnelt ganz dem Dampf, oder einer Blase auf dem Wasser, / denn so wie Dampf schnell vergeht, so ist es [auch] mit dem Menschen, / und wie eine Blase auf dem Wasser ist er nicht von Dauer; / ihm ähnelt das ganze Geschlecht Adams. / Er verschwindet alsbald wie ein Tautropfen, stiftet aber viel Nutzen. / Man kann einen anderen mit Dampf vergleichen [...] / Wie ein Quell strebt er zum Meer [= der Unendlichkeit], oder wie ein Pfeil zum Ziel. / Wie ein Blitz leuchtet er kurz auf, / und schadet sehr den Menschen in der Welt. / Oder er geht schnell vorüber, wie eine Wolke [...]. / Unser Leben ist ein Schatten, ein kurzer Traum [...] / Jeder Mensch verwelkt wie eine Blume, / am Morgen blüht er, am Abend ist er nicht mehr. / Er gleicht sehr dem grünen Gras, / bald mäht ihn die Sense des Todes. ${ }^{27}$

26 Vgl. bei van Ingen 1966: 62-63, die „Bildreihen“ der Vergänglichkeit in der deutschen Barockdichtung.

27 „Добре человек паре прировняся / или говором на воде назвася, / Яко бо пара скоро изчезает, / тако человек вмале преминает, / И яко говор стоит мало время, / ему подобно все Адамле семя. / Ин, яко роса, вскоре опадает, /

обаче ползу многу содевает. / Дыму инаго мощно прировняти [...]. / Яко источник, тщится к океану, ли яко стрела к целю написану. / Яко молния ин кратко блистает, / но много в мире людем повреждает. / Ин, яко облак, воскоре преходит, [...]. / Сень и сон краткий есть житие наше [...]. / Всякий человек, як цвет, увядает, / утро ли цветет, и вечер опадает. / Траве зеленой зело подобится, / скоро бо смерти косою косится“ (11a, V. 37-58). Zum Wort „говор“ 
Derlei Häufungen der Bildsprache findet man auch an anderen Stellen, wie etwa im Lob der verstorbenen Zarin (11b, V. 31-44). Diese „Überfunktion des Stils“ ist ebenfalls ein Kennzeichen des literarischen Barock (Friedrich 1964: 545-567).

Von der Vergänglichkeit handelt auch die Totenklage der Zarentöchter. Hier reihen sich die Antithesen. Die Zeit bringt den Menschen nichts als Unglück: Auf die Freude am Abend folgt eine „Tränenschwemme“ am nächsten Morgen; „wer heute gesund, schön und berühmt ist, / der ist am nächsten Tag krank, häßlich und ruhmlos“. Es folgen Beispiele aus der klassischen Antike: „[W]ie Krösus glänzt heute einer wegen seines Reichtums, / morgen ist er arm wie Irus [= der Bettler der Odyssee], / Heute strahlt ein Demokrit vor Freude, / morgen zergeht Heraklit vor Kummer, / In der Welt gibt es keine Beständigkeit, das wissen wir wohl, / unerschütterlich hält sie sich in Unbeständigkeit“ etc. ${ }^{28}$ Der letztere Satz enthält eine paradoxe Zuspitzung, wie sie für den Barockstil wiederum typisch ist: 'Beständig ist nur die Unbeständigkeit' ${ }^{29}$. So etwas findet sich auch in der einleitenden Prosarede, wo von der Tröstung der Tränen durch Tränen die Rede ist: „slezy slezami utoljatsja“ (S. 263).

In der Totenklage der russischen Städte ist die Vergänglichkeit Gegenstand einer weiteren Reihung. Simeon verwendet hier einen westeuropäischen Gemeinplatz: die anaphorisch wiederholte Frage nach dem Verbleib der irdischen Dinge. 'Vergänglich sein' bedeutet bei ihm auch 'in Vergessenheit geraten'. Die Wurzel des Übels ist die Zeit, diese Helfershelferin des Todes; in der lateinischen Urfassung beginnt die Reihung stets mit den Worten „Ubi sunt ...?“30. In den Threnodien heißt es:

Wo ist Ninive geblieben, wo das berühmte Troja? / Die Zeit hat ihre Spuren verwischt. / Wo sind die sieben [Welt-]Wunder geblieben, / an die sich die alten Zeiten erinnern? / Die Zeit zerstört alles, überführt es ins Nichtsein / und umgibt es mit einer Wolke des Vergessens / Was die Zeit für die Dinge ist, das ist der Tod für die Menschen, / Seit jeher verwandelt er Alles in Moder und Asche. / Wo sind die Patriarchen geblieben, die Herrscher, die Prophe-

vgl. Dal’ 1955 I: 364. Es wird hier mit der Redewendung „пузырь на воде“(„Blase auf dem Wasser“) assoziiert, also mit Vergänglichkeit.

28 „Иде же радость на вечер блистает, / там утро слезный потоп проливает. / Здрав кто днесь, силен, красен и преславен, / немощен утро, нелеп и безславен. / С Крезом богатствы некто днесь славится, / утро со Иром в нищете равнится. / Днесь кто Демокрит радостми светлеет, / утро Ираклит от печали тлеет. / Несть постоянства в мире, добре знаем, / в непостоянстве стоит невреждаем“ (3а, V. 11-19).

29 Vgl. Lachmann 1970 über die Barocktradition des acumen bei Simeon.

30 Vgl. die „Ubi sunt...“-Zitate bei Delumeau 1983: 19-20. Vgl. auch den Kommentar von Anthony Hippisley in: Polockij 2017: 581. Er zitiert den Refrain von François Villons „Ballade des dames du temps jadis“ von 1533: „Mais où sont les neiges dantan“ - „Aber wo ist der Schnee von gestern?“ 
ten, / die berühmten Frauen, die tüchtigen Recken? / Alle hat der Tod ins Grab genommen / und von ihnen kaum eine Erinnerung gelassen. ${ }^{31}$

Wertvoll ist bei Simeon nur das Ewige, Unvergängliche; der Begriff der Zeit verschwimmt mit dem des Todes und der irdischen Wirklichkeit. Es äußert sich der contemptus mundi, die Weltverachtung der christlichen Tradition (vgl. Le Goff 1982: 159, oder Delumeau 1983: 15-43). In der Totenklage der Städte entspricht ihr die ebenso traditionelle Formel von der vanitas vanitatum (,suetstvo suetstv“ 3a, V. 9); bekanntlich geht sie auf das Alte Testament und den Ekklesiasten zurück: „Es ist alles ganz eitel, sprach der Prediger, es ist alles ganz eitel“ (Koh. 1, 2).

Alles Irdische ist wertlos, das Menschenleben - nicht von Dauer. Im traditionellen Glauben des Christentums und auch bei Simeon ist der Tod kein natürlicher Vorgang, sondern eine Strafe Gottes für die Sünde Adams und Evas; vgl. Röm. 5: 12-21. In der lehrhaften Einleitung der ersten Totenklage ist der Sündenfall als katastrophales Ereignis der Heilsgeschichte gleichbedeutend mit dem Einbruch des Todes und des Bösen: „Woher kam, nachdem alles so schön war, / das Böse in die Welt und der Tod auf den Thron, / Der unersättliche und unerbittliche Tod, der alles mit seinen Zähnen verschlingt, / Dabei nicht auf den Rang der Menschen achtet / Und alle in die finsteren Gruben zerrt? [...] “32. Obwohl Simeon nur die Mächtigen dieser Erde nennt, erscheint der Tod hier in seiner traditionellen Rolle als der große Gleichmacher. In diesem Sinn wendet sich der Ältestenrat in seiner Todesklage auch an den „,blinden Tod“, der weder auf Rang oder Namen achtet: „O smerti slepaja!“ (5a, V. 25).

Ebenso wie im Westeuropa der frühen Neuzeit verbindet sich das Todesthema bei Simeon mit dem Abstoßend-Makabren ${ }^{33}$, der Extremform des contemptus mundi. In der Totenklage des Ältestenrats heißt es: Der Tod will „alles in Staub und Asche verwandeln / alles Fleisch mit Würmern und Fäulnis bedecken“34. So liest man es auch im Abschiedswort der verstorbenen Zarin, in der Apostrophe an

31 „Где Нинивия, где славная Троя? / Время погуби и с следом своя. / Где суть седмь дива [...], / иже старыя веки воспоминают? / Вся губит время, в небытство приводит, / и забвения облаком заводит. / Что время вещем, то смерть человеком, / вся в тлю и пепел вращает от веков. [...] / Где патриарси, царие, пророцы, / славныя жены, силнии отроцы? / Вся смерть во гробех своих заключила / и едва неких память оставила“ (8a, V.13-18, 25-28).

32 „Всем благим бывшим, откуду родися / злоба во мире и смерть воцарися, / Смерть несытая и неумолима, / вся ядущая зубама своима, / Не смотрящая на вся людей саны, / вся похищая до темныя ямы? / Венцы и скиптры царей похищает / и сами в темных гробех заключает / [...]““(1a, V. 13-28).

33 Vgl.: Huizinga 1969: 190-208, Ariès 1977: 112-125, Delumeau 1983: 15-128. Tschižewskij 1968 spricht vom Hässlichen in der slavischen Barockliteratur, allerdings ohne Bezug zur Religion.

34 „Вся в прах и пепел тщится изменити / червми и тлею вся плоти покрити“ (5а, V. 29-30). 
ihren Gatten. Wenn auch sie, die Zarin, vom Tod als dem Gleichmacher spricht, so ist das ein weiteres Zeichen von Demut; der christlichen Relativierung des weltlichen Glanzes muss sich auch ihr Gatte fügen:

Siehe, Aleksej, wie die Knochen deiner Gattin, / jetzt vom Fleisch entblößt sind. / Wisse, oh du herrlicher Zar, dass der Tod / alles gleichmacht, / Und auch mein Fleisch ganz zu Staub verwandelt. / Die Verwesung hat mich umfangen, der Kot ist mir Schwester und Mutter, / Der Sarg ist mein Bett, und ich muss lange liegen. / Blicke auf mich, sei dessen für dich selber eingedenk, / dass es Unsterblichkeit nur im Himmel gibt ${ }^{35}$.

Die christliche Weltverachtung zeigt sich bei Simeon auch im Lob der Askese. Im Trostgedicht der „Enthaltsamkeit“ wird die Zarin mit den folgenden Worten gepriesen:

Sie lebte alle Tage mit Enthaltsamkeit, / aß nur, um sich zu stärken, nicht wegen des Wohlgeschmacks. / Sie wollte ihr Fleisch endgültig abtöten, / um den inneren Menschen zu beleben, / auf dass der Geist über das Fleisch herrsche, / damit das Fleisch sich daran gewöhne, dem Geist zu gehorchen. / Im Zarenpalast gab es für sie eine Einsiedelei, / in der sie schweigend Gott diente ${ }^{36}$.

Wie man hinzufügen kann, entsprach dieses Lob weitgehend den zeitgenössischen Vorstellungen davon, wie eine Zarin zu leben hatte (Zabelin 2001: 284340). Auch in dieser Hinsicht äußert Simeon also keine persönliche Meinung oder Beobachtung, sondern folgt einer Norm, die auch für den Zarenhof verbindlich war. Das asketische Motiv findet sich auch im Abschiedswort der Zarin:

Und ihr, meine lieben Töchter, / hört auch ihr auf die Stimme eurer Mutter aus dem Grab. / Lebt mit Fasten, Gebeten und Liebe, / Und bewahrt alle Tage eure Keuschheit. / Verachtet alles Schöne dieser Welt, / und bereitet eure Herzen auf das Himmelreich vor. / Hinieden ist alles vergänglich, alles vergeht in der Welt, / ewig währt nur was im Himmel ist. ${ }^{37}$

35 „Царица бывши, костьми обнаженна. / Веждь, Царю славный, како смерть равнает / вся и плоть мою во прах прелагает. / Тля мя всю обьят [sic], гной мне сестра, мати, / гроб за постелю, а долго лежати. / Зря же мене, разсуждай о себе, / яко безсмертность токмо в самом небе“ (13, V. 79-86). Die Bedeutung von „gnoj“ als „Kot“ entspricht dem west- und südrussischen Sprachgebrauch; vgl. Pavlovskij 1972 I: 249, der „gnoj“ auch mit „Dünger“ übersetzt. Vgl. auch Vasmer 1953: 280-281. Im Kirchenslavischen wird das Verb „gnoiti“ mit „Darmentleerung“ assoziiert (D'jačenko 1899: 125).

36 „[...] Яже по вся дни воздержно живяше, / в сил скрепление, не в сладость ядяше. / Плоть свою тщася вконец умертвити, / человека же внутрьня оживити, / Дабы дух плоти могл повелевати, / плоть же навыкла духа послушати. / В царстей полате ей пустыня бяше, / в ней же безмолвно Богу работаше“ (6b, V. 33-40).

37 „И вы, о Дщери, любая утроба, / тожде приимите от матерня гроба. / В постах, в молитвах, в любви живите, / целомудрие по вся дни храните. / Красная мира сего 
In der Apostrophe der Zarin an ihre Söhne war von Askese allerdings nicht die Rede, das Gebot der Weltverachtung gilt, wie man sieht, nur für die Frauen. Auch ist die Mahnung der Zarin, sich „Weisheit zu erwerben“, nur für die Söhne bestimmt: „Tjažite mudrost'“ (13, V. 145).

\section{Tod und Jenseits}

Vergänglichkeit, Verwesung, gnadenloser Tod - diese düsteren Vorstellungen, die in den Threnodien so wortreich ausgebreitet werden, haben die moralische Bedeutung eines memento mori: Das ständige Bewusstsein der eigenen Sterblichkeit soll den Menschen zu einem tugendhaften Lebenswandel veranlassen, auf dass er einst die ewige Seligkeit erlange; das ganze Leben ist eine Vorbereitung auf den Tod. Dieses christliche Todespathos hat bei Simeon außer der lehrhaften auch eine kompositorische Bedeutung: Sie bildet eine Kontrastfolie, vor der die paulinische Botschaft um so triumphaler hervortreten kann - die frohe Botschaft vom Sieg, den Christus mit seinem Kreuzestod und seiner Auferstehung über den Tod errungen hat. Bekanntlich heißt es im Ersten Korintherbrief: „Tod, wo ist dein Stachel? Tod, wo ist dein Sieg?“ (Kor. 1, 15: 55).

Den Stachel des Todes finden wir auch bei Simeon, im Trostgedicht der allegorischen Weisheit. Dieses Motiv verbindet sich hier mit der paulinisch-paradoxen Vorstellung vom wahren Leben der Gerechten, das erst nach dem Tod beginnt; nicht der körperliche Tod ist der wahre Tod, sondern die ewige Verdammnis: Die Zarin „ist nicht gestorben, sondern sie beginnt das ewige / Leben mit Gott und besiegt den Tod. / Wer für die Welt, für das Fleisch, für die Hölle lebt / Der fühlt am Ende den Stachel des Todes“38.

Für die Zarin ist der Tod kein Ende, sondern der Übergang zu einem neuem Leben, zur ewigen Seligkeit. In den Threnodien begegnen wir dieser Vorstellung auch im zweiten der neun Embleme: Es hat den Titel „Er stirbt, und lebt doch“ „Umiraet, da živit“ (S. 327). Damit ist der Tod des Phönix und seine Wiederauferstehung aus der Asche gemeint. Solche Synkretismen von Heidnischem und Christlichem findet man bei Simeon auch an anderen Stellen; im russischen Ba-

презирайте, / в горнее царство сердца возвождайте. / Зде вся суть тленна, преходит во мире, / вечна суть, яже во небесном дворе“ (13, V. 160-167). Was das Wort „utroba“ betrifft, so kann es neben 'Schoß' auch 'Herz' bedeuten (D’jačenko 1899: 768), hier in der Bedeutung einer Liebkosung, die ich mit der Anrede „liebe Töchter“ wiedergebe.

38 „Не умре она, но жизнь зачинает / вечную с Богом, а смерть попирает. / Кто миру, плоти, аду жителствует, / той жало смерти при конце чювствует“ (5b, V. 31-34). 
rock war derlei weit verbreitet und wurde nicht als ungehörig empfunden (Morozov 1962: 24).

Bei Simeon hat der Tod eine zweifache Bedeutung. Zum einen ist das der „böse Tod“, der den „Lebensfaden“ der Zarin zerschnitten hat ${ }^{39}$ (auch das ist ein Motiv aus der heidnischen Antike: Es verweist auf Morta, die dritte der Parzen). Zum anderen ist das aber auch der schöne Tod einer Zarin, die mit ihrer „Gottesfurcht“, ihrer „Fremdenliebe“, ihrer „Barmherzigkeit“ und ihrer klösterlichen „Enthaltsamkeit“ das Leben einer Heiligen geführt hat. In dem Trostgedicht, das auf die Totenklage des Zaren folgt, heißt es daher: „Sie ist nicht gestorben, sondern ruht im Schlaf, / Der Tod der Gerechten wird Schlaf genannt / [...] “40. Der „Schlaf“ hat hier also keine euphemistisch mildernde, sondern eine hoffungsvolle Bedeutung, denn der 'Entschlafenen' stand mit der Wiederauferstehung des Fleisches am Ende der Zeit ein 'Erwachen' bevor.

Zwar beten die Hinterbliebenen für das Seelenheil der Zarin, wie etwa die Geistlichkeit (4a, V. 73-78) oder die Klöster (6a, V. 25-30, 33-40). Das bedeutet jedoch nicht, dass dieses Seelenheil in irgendeiner Weise gefährdet sei. Und wenn die Zarin ihren Gatten anfleht, für sie zu beten (13, V. 69-72), so ist das wiederum kein Ausdruck von Furcht, sondern von christlicher Demut. In den Threnodien steht es außer Frage, dass die Zarin zur ewigen Seligkeit gelangt. Im Trostgedicht der Weisheit heißt es daher in wiederum paulinischer Wendung: „Sie ist nicht gestorben, sondern beginnt / das ewige Leben mit Gott und besiegt den Tod“ “41. Die Zarin ist eine Heilige, der, wie man folgern kann, nach dem Tod die „Qualen“ - „mytarstva“ - der übrigen Sterblichen erspart bleiben ${ }^{42}$. Dass sie inzwi-

39 „[С]мерть лютая нить жизни прерьваше“ (6a, V. 8).

40 „Не умре она, но сном почивает, / смерть преподобных сном ся нарицает“ (1b, V. 65-66).

41 „Не умре она, но жизнь зачинает / вечную с Богом, а смерть попирает“ (5b, V. 31-32).

42 Das Motiv der „mytarstva” findet sich im Abschiedswort der Zarin. Auch hier ist das kein Ausdruck von Furcht, sondern von Demut. Die Zarin wendet sich an ihren Gatten: ,Jetzt brauche ich deine Hilfe, / damit ich ohne Hindernis in den Himmel gelange, / dass ich die Schwellen der jenseitigen Qualen überwinde / und von den Seelenfeinden [= den Dämonen] nicht gekränkt werde“ „Ныне помощи мне от тебе требе, / да беспрепятно могу стати в небе, / Воздушных мытарств да пребуду праги, / не оскорбленна душевными враги“ (13, V. 101-104). Im Slovar’ 1992, II: Sp. 1607, werden die „mytarstva“ folgendermaßen bestimmt: als „die Offenlegung der Sünden, die [Buß-]Qual der Seelen im Jenseits, nachdem sie die Körper verlassen haben, noch vor dem Urteil Gottes“; vgl. auch Bulgakov [1965]: 381-382. In der Ostkirche gehören die „mytarstva“ zum Prozess der Gottwerdung nach dem Tod (obožestvlenie) und sind deshalb nicht mit dem katholischen Fegefeuer zu verwechseln. Die „mytarstva“ sind keine Strafe; der Orthodoxie mit ihrer „mystischen Grundhaltung“ sind die quasi-juristischen, rationalen Vorstellungen der westlichen Christenheit fremd; Schuld und Sühne haben für sie eine viel geringere Bedeutung; vgl.: Meyendorff 1960: 169-170, Benz 1971: 39-48; Živov 2010a. Andererseits ist jedoch nicht zu übersehen, dass sich die Zarin das Himmelreich mit ihren guten Werken durchaus 'verdient' hat, wie das der 
schen die ewige Seligkeit genießt, ist denn auch der oft wiederholte Trost für die Trauergemeinde. In dem Trostgedicht „aller Tugenden“, das die Todesklage des „russischen Reiches“ ergänzt, ist der Tod der Zarin nur ein Ortswechsel: „Wer fromm gelebt hat, der stirbt nicht, / sondern siedelt über ins bessere Leben“43. Marija Il'inična muss also nicht auf das Jüngste Gericht warten, wie die übrigen Menschen.

\section{Westen und Osten}

Mit Blick auf die verstorbene Zarin zeigt sich bei Simeon eine bemerkenswerte Heilsgewissheit. Das führt uns zu der allgemeineren Frage nach dem Verhältnis der Threnodien zur europäischen Tradition - eine Frage, die wegen Simeons Herkunft aus dem westlichen Teil des Zarenreiches naheliegt. Das Bindeglied zum Westen waren die ukrainisch-weißrussischen Bildungsstätten, die polnische Kultur und die neulateinische Literatur (Sazonova 2006: 34-41).

Der westliche Einfluss zeigt sich bei Simeon an der Nähe zum Barockstil, an der Bild- und Formelsprache der Vergänglichkeit, am contemptus mundi, dem Abstoßend-Makabren und der Allegorik des Sensenmanns ${ }^{44}$. Umso auffälliger sind die Unterschiede. Im Westeuropa der frühen Neuzeit herrschte die Vorstellung vom Jüngsten Gericht als einem dies irae und von Gott als einem „schrecklichen Gott“"45: Auch die Gerechten mussten fürchten, nicht zu den Auserwählten zu gehören. Aus dem Bewusstsein abgrundtiefer Sündhaftigkeit entstand so eine weitverbreitete „Unsicherheit über den eigenen Gnadenstand“46.

Ganz anders verhält es sich bei Simeon, wie nicht nur in der Trostrede der allegorischen Hoffnung deutlich wird (2b). Dasselbe gilt für die übrigen Syllabiker: Als Geistliche, die sie waren, vermieden sie die Strenge des westlichen Barock und sorgten sich um das „seelische Gleichgewicht“ ihrer Gemeinde (vgl. Pančenko 1973: 199-208, hier 200). Auch Simeon liegt es fern, die Gläubigen nach westlichem Vorbild mit Schuldgefühlen zu belasten, sie mit dem Höllenfeuer zu

katholischen Lehre entspricht. Zum Einfluss des Katholizismus auf Simeon vgl. Majkov 1889: 65-67.

43 „Кто благо живе, той не умирает, но на лучьшую жизнь ся преселяет“ (11b, 15-16).

44 Vgl. Sukina 2011: 316: Das Abstoßend-Makabre sei erst im 17. Jahrhundert in die altrussische Kunst eingedrungen. Die personifizierende Darstellung des Todes gab es schon seit Mitte des 16. Jahrhunderts (Vilinbachova 2002: 258, 267).

45 Vgl. Delumeau 1983: 321-331: „L’homme criminel et le Dieu terrible“.

46 Vgl.: van Ingen 1966: 317; vgl. auch: Ariès 1977: 152-154, Delumeau 1983: 334, 339-363; Vovelle 1983: 276, spricht mit Blick auf die Barockepoche von einer „,angoisse du salut“. 
erschrecken und auf diese Weise zur Buße zu drängen ${ }^{47}$. Ihm geht es nicht um Drohung, sondern um Zuversicht, nicht um Höllenqualen, sondern um die himmlische Seligkeit und den sicheren Weg zu ihr. Diese Zuversicht äußert sich auch in seinen Gedichten über den Tod, die man im Blumenreichen Weingarten findet (Polockij 2000 III: 141-155). Aus dieser Sicht hat der Tod seinen Schrecken verloren.

Freilich ist bei all dem zu bedenken, dass die Rede von ewiger Verdammnis in der Funeralpanegyrik eines Hofdichters wohl fehl am Platze gewesen wäre. Zwar wurde im Russland des XVII. Jahrhunderts das Jüngste Gericht und die Höllenstrafe dargestellt, in der erzählenden Prosa und auch auf den Ikonen (Vilinbachova 2002). Dennoch gilt, dass die Ostkirche ihre Gläubigen schonender als die westlichen Kirchen behandelte. In Russland war die Lehre von der ewigen Höllenstrafe seit jeher umstritten (vgl.: Benz 1971: 43, Bulgakov [1965]: 388); der Begriff der Todsünde spielte kaum eine Rolle (ebd.: 165, vgl. Sukina 2011: 165). Das Wort 'грех' bedeutet im Altrussischen nicht nur 'Sünde', sondern auch 'Fehler'48 - die Sünde war weniger Ausdruck von menschlicher Hoffart, als von menschlicher Schwäche. Durch fleißiges Beten konnte man die Sünder nicht nur vor der Hölle bewahren, sondern sie sogar auch aus der Hölle retten (Sukina 2011: 320). Das hoffnungsvoll-tröstliche Element von Simeons Threnodien ist daher kein Zugeständnis an das höfische Publikum. In Russland war das vielmehr eine Selbstverständlichkeit: Wer sich auf Erden bemühte, ein guter Christ zu sein, brauchte den Tod nicht zu fürchten; Simeon war denn auch kein Anhänger der im Westen sehr verbreiteten Vorstellung, nur „Wenige“ seien „auserwählt“49. Und im Zweifelsfall konnte man auf die Fürsprache der Gottesmutter hoffen und auf die grenzenlose Barmherzigkeit Gottes ${ }^{50}$.

47 Vgl. Delumeau 1978: 197-231, Favre 1978: 69-97: „L'église et les terreurs salutaires“; Vovelle 1983: 237-364. Vgl. auch van Ingen 1966: 356-357, über die „Verbreitung von Furcht und Schrecken“ durch die protestantischen und katholischen Prediger.

48 Vgl. Sreznevskij 1893: Sp. 604: altrussisch „грех“ wird hier auch mit „ошибка“ umschrieben. 49 Kennzeichnend in dieser Hinsicht ist ein Gedicht aus Simeons Blumenreichem Weingarten (Vinograd mnogocvetnyj). Der Titel lautet: „Nur Wenige werden gerettet“ - „Malo spasajuščichsja“ (Polockij 1999: 282-284). Tatsächlich ist in diesem Gedicht die Hölle viel reicher bevölkert, als der Himmel. Allerdings wussten Simeons Leser, dass die ewige Verdammnis vor allem den Ungläubigen drohte (Pančenko 1973: 200). Wenn dagegen ein Christ den rechten Weg einschlug, dann erlangte er die ewige Seligkeit, denn „Gott schaut nicht auf die Zahl der Menschen, sondern auf die guten Werke“ - „[...] не по числу лиц, но дел благих Бог спасает [...]“ (ebd.: 284): Gott in seiner Gerechtigkeit und Güte ist also, mit anderen Worten, keineswegs bestrebt, die Zahl der Seligen möglichst klein zu halten. - Den Hinweis auf dieses Gedicht verdanke ich Pančenko 1973: ebd.

50 Vgl. Živov 2010a: Der Mensch konnte das Seelenheil auch ohne besondere Anstrengung erlangen, durch Fürbitte und sogar durch Zufall (ebd.: 125); der Begriff der Sünde war unklar und hatte keine große Bedeutung (ebd.: 147). Vgl. auch Živov 2010b: 64-65, und Sukina 2011: 130-131. 


\section{Contemptus mundi?}

Simeon konnte bei seinen Lesern den „eschatologischen Optimismus“ des östlichen Christentums voraussetzen (vgl. Dergačeva 2003: 146, Dergačeva 2017: 68, Živov 2010a: 124). Wie aber steht es mit dem Negativismus des contemptus mundi?

Erneut rückt hier die Theologie der Ostkirche ins Blickfeld. Im Gegensatz zum westlichen Christentum war das Leben aus ihrer Sicht kein Jammertal, kein ,finsterer und leerer Korridor", den man durchschreiten musste, um ins Himmelreich zu gelangen ${ }^{51}$. Dasselbe gilt für Simeon; ebenso wie die Friedensliebe des sechsten Trostgedichtes sollte man seinen contemptus mundi daher nicht allzu wörtlich nehmen - bei ihm ist das nicht viel mehr als ein Gemeinplatz, mit dessen wortreicher Entfaltung er als dichtender Rhetor glänzen konnte ${ }^{52}$. Dasselbe gilt für die Motivik des Abstoßend-Makabren. Wie wenig ernstzunehmen sie bei Simeon ist, zeigt schon ein Blick auf seine persönliche Lebensführung: Er war kein asketischer Einsiedlermönch; als geschickter Höfling und öffentlich wirksamer Kirchenmann lebte er dank herrscherlicher Munifizenz in komfortablen Verhältnissen ${ }^{53}$.

Gegen Simeons Weltverachtung spricht in den Threnodien auch die Anhänglichkeit des russischen Reiches an die verstorbene Zarin - eine Anhänglichkeit, die den Gegenstand und das staatsfromme Pathos dieser Dichtung ausmacht: Hienieden war durchaus nicht alles eitel. In dieselbe Richtung weist mit besonderer Eindringlichkeit die Totenklage der Zarensöhne mit dem zärtlichen Rückblick auf die verstorbene Mutter. Hier vernimmt man einen geradezu intimen Ton. Simeon war ja nicht nur Hofpoet und -prediger, sondern auch Lehrer der Zarenkinder, denen er, wie anzunehmen ist, auch persönlich nahestand. In der Todesklage der Zarensöhne geht es jedenfalls um ein Verhältnis zur Verstorbenen, wie es herzlicher kaum sein könnte:

Oh, du unsere Mutter, süße Mutter, / in der Welt werden wir dich jetzt nicht mehr sehen. / Wem hast du uns Waisen an deiner Stelle anbefohlen, / Wenn wir deiner Mutterliebe nicht mehr teilhaftig sind? / Wen werden wir alle Tage begrüßen, / wen werden wir morgens und abends küssen? / Wem sollen wir uns mit einer Verbeugung nähern / um zu wessen Mutterliebe die Augen zu erheben? / Du hast uns alle Tage mütterlich geküsst / und uns gelehrt,

51 Vgl. Bulgakov [1965]: 375, der in diesem Zusammenhang sogar von einem ,pseudoasketischen Nihilismus" spricht. Vgl. auch Meyendorff 1960: 175-176, über das Gottesreich auf Erden, das sich in der orthodoxen Liturgie offenbart - eine Vorstellung, die mit dem contemptus mundi der westlichen Kirchen nicht zu vereinbaren ist.

52 Über Simeons Redekunst vgl. Tatarskij 1886: pass.

53 Vgl.: Tatarskij 1886: 202-212. 
stets Gott zu fürchten. / Du warst uns eine Lehrerin der guten Sitten, / oh, du unsere geliebte Mutter! / Wie sollen wir jetzt ohne dich leben, / und zu wem unsere Köpfe neigen?54

\section{Exkurs: Freny und Treny}

Als mögliches Vorbild der Threnodien hat man Jan Kochanowskis Treny von 1580 genannt (Hippisley [1985]: 10). Tatsächlich folgte Simeon diesem Dichter mit seiner versifizierten Psalmenübertragung von 1678 (Eremin 1953: 240-242). Mit der Begräbnisdichtung war das jedoch eine andere Sache. Zwar besteht auch Kochanowskis Werk aus einer Reihe von lyrischen Monologen; daher die Pluralform Treny. Gleichwohl sind die Unterschiede nicht zu übersehen. Vor allem hat Kochanowski sein Werk nicht zu einem öffentlichen, sondern zu einem privaten Anlass geschrieben - zum Tod seiner Tochter Urszula. Eine „,rhetorische Grundhaltung“ sucht man hier vergebens. Das war eine lyrische Dichtung von nuanciertem Gefühlsausdruck, kein Werk der Hofliteratur.

Wie aber steht es mit den Gattungsnamen Treny und Freny? In Russland findet sich Freny meines Wissens allein bei Simeon und dies nur in seinem „Büchlein“ auf den Tod der Zarin, also nicht mehr in dem Werk von 1676 auf den Tod ihres Gatten: Glas poslednij ko gospodu Bogu - Eine letzte Stimme, an Gott gerichtet. Nach Simeon sollte sich in der russischen Literatur der Gattungsname „Klage“ (,plač'“) einbürgern; oft haben die Gedichte auch einen Titel wie „Na končinu...“ „Auf das Ableben von...“.

Was die Bezeichnung Treny betrifft, so war sie in der polnischen Literatur vor Kochanowski nicht gebräuchlich; er hat sie wohl unmittelbar aus dem Griechischen ('threnos') oder dem Lateinischen ('threnus') übernommen (vgl. Davie 2001: XI). Hätte Simeon diesen Gattungsnamen also Kochanowski zu verdanken? Das ist immerhin möglich, trotz der byzantinisch-kirchenslavischen Schreibweise Freny anstelle von Treny. Allerdings hat man zu bedenken, dass nach Kochanowski auch andere polnische Dichter den Gattungstitel Treny verwendeten, etwa Tobiasz Wiszniowski (1585), Zbigniew Morsztyn (1682), oder Stanislaw Grochowski (1608), oft in Verbindung mit einer zyklischen Komposition (Pelc 1990). Simeon hätte den Gattungsnamen von jedem dieser Dichter übernehmen können.

54 „0, мати наша, пресладкая мати, / уже нам в мире тебе не видати. / Кому нас, сирых, за себе вручила, / еда к нам милость матерню забыла? / Кого по вся дни будем поздравляти, / утро и вечер кого нам лобзати? / К кому с поклоном имамы ходити / к матерней любви очи возводити? / Ту ны по вся дни матерски лобзаше, / Божию страху выну поучаше. / Благонравию ты учителница, / о, любезная нам родителница. / Ныне без тебе како нам пожити, / до кого главы наши приклонити?“ (2a, V. 23-36). 
Danksagung: Die Anregung zu diesem Aufsatz verdanke ich einem informellen Kolloquium mit Victoria Frede und Luba Golburt über das Todesthema in der russischen Lyrik. Dank schulde ich auch Elena Marasinova, Sergej Nikolaev, Andreas Ebbinghaus und Walter Kroll.

\section{Literaturverzeichnis}

Alt, Peter-André. 1995. Begriffsbilder. Studien zur literarischen Allegorie zwischen Opitz und Schiller. Tübingen: Niemeyer.

Ariès, Philippe. 1977. L'homme devant la mort. Paris: Éditions du Seuil.

Benz, Ernst. 1971. Geist und Leben der Ostkirche. Zweite, durchgesehene und verbesserte Auflage. München: Fink.

Bulgakov, Sergij. [1965]. Pravoslavie. Očerki učenija pravoslavnoj cerkvi. Paris: YMCA-Press.

Burkhart, Dagmar 1997. Der byzantinische (hagiographische) Threnos und sein Einfluß auf die orthodoxen Slaven. In Zeitschrift für Slawistik 42: 316-327.

Dal', Vladimir. 1955. Tolkovyj slovar' živogo velikorusskogo jazyka. Bd. I-IV. Moskva: Gosudarstvennoe izdatel'stvo inostrannych i nacional'nych slovarej.

Davie, Donald. 2001. Foreword. In Treny. The Laments of Kochanowski. Transl. by Adam Czerniawski. Ed. and annot. by Piotr Wilczek. XI-XIV. Oxford: Legenda.

Delumeau, Jean. 1978. La Peur en Occident (XIVe-XVIIle siècles). Une cité assiégée. Paris: Fayard. Delumeau, Jean. 1983. Le péché et la peur. La culpabilisation en Occident (XIIle-XVIIle siècles). Paris: Fayard.

Dergačeva, Irina V. 2003. Posmertnaja sud'ba $i$ «inoj mir» v drevnerusskoj knižnosti. Moskva: Krug.

Dergačeva, Irina V. 2017. Russkaja i evropejskaja tanatologičeskie paradigmy XIV-XVII v. v sravnitel'nom aspekte. In Drevnjaja Rus'. Voprosy medievistiki, ijun' 2017, Nr. 24: 69-73.

D’jačenko, Grigorij. 1899. Polnyj cerkovno-slavjanskij slovar' (so vneseniem v nego važnejšich drevne-russkich slov i vyraženij) [...]. Moskva: Tipografija Vil'de.

Domostroj. 1990. Hrsg. von Vladimir V. Kolesov, V. V. Roždestvenskaja, V. V. Kolesova \& M. V. Pimenova. Moskva: Sovetskaja Rossija.

Eremin, Igor' P. 1953. Simeon Polockij - poèt i dramaturg. In Simeon Polockij, Izbrannye sočinenija, 223-260. Moskva \& Leningrad: Izdatel'stvo Akademii nauk SSSR.

Eremin, Igor' P. 1966. Poètičeskij stil' Simeona Polockogo. In Ders., Literatura drevnej Rusi (Ėtjudy i charakteristiki), 211-233. Moskva \& Leningrad: Nauka.

Esteve-Forriol, José. 1962. Die Trauer- und Trostgedichte in der römischen Literatur, untersucht nach ihrer Topik und ihrem Motivschatz. Diss. phil. München.

Favre, Robert. 1978. La mort dans la littérature et la pensée française au siècle des lumières, Lyon: Presses universitaires.

Friedrich, Hugo. 1964. Epochen der italienischen Lyrik. Frankfurt/M.: Klostermann.

Grebenjuk, Vasilij P. 1982. Rifmologion Simeona Polockogo (Istorija sozdanija, struktura, idei). In Simeon Polockij i ego knigoizdatel'skaja dejatel'nost'. Hrsg. von Andrej N. Robinson. Moskva: Nauka.

Hippisley, Anthony. [1985]. The Poetic Style of Simeon Polotsky. Birmingham: Dept. of Russian Language \& Literature, University of Birmingham. 
Huizinga, Johan. 1969. Herbst des Mittelalters. Stuttgart: Kröner.

Košeleva, O’lga E. 2000. «Otchodja ot sveta sego». Častnaja žizn' moskovskoj èlity XVII veka čerez prizmu zaveščanij. In Čelovek v mire čuvstv. Moskva: Rossijskij gosudarstvennyj gumanitarnyj universitet.

Krummacher, Hans-Henrik. 1974. Das barocke Epicedium. Rhetorische Tradition und deutsche Gelegenheitsdichtung im 17. Jahrhundert. In Jahrbuch der Deutschen Schillergesellschaft. Hrsg. von Fritz Martini et al. 18. Jahrg.: 89-147.

Lachmann, Renate. 1970. Die Tradition des ostroumie und das acumen bei Simeon Polockij. In Slavische Barockliteratur I. Hrsg. von Dmitrij Tschižewskij, 41-59. München: Fink

Le Goff, Jacques. 1982. La civilisation de l' occident médiéval. Paris: Arthaud.

Longworth, Philip. 1984. Alexis, Tsar of All the Russias. London: Secker \& Warburg.

Majkov, Leonid N. 1889. Simeon Polockij. In Ders., Očerki iz istorii russkoj literatury XVII i XVIII stoletij, 1-162. Sankt-Peterburg: Izdanie A.S. Suvorina.

Meyendorff, Jean. 1960. L'Église orthodoxe hier et aujourd'hui. Paris: Éditions du Seuil.

Morozov, Aleksandr A. 1962. Problema barokko v russkoj literature XVII - načala XVIII veka (Sostojanie voprosa i zadači izučenija). In Russkaja literatura 3: 3-38.

Müller, Günther. 1929. Höfische Kultur der Barockzeit. In Hans Naumann \& Günter Müller, Höfische Kultur. Halle: Niemeyer.

Müller, Günther. 1957 [1927]. Deutsche Dichtung von der Renaissance bis zum Ausgang des Barock. Darmstadt: Wissenschaftliche Buchgesellschaft.

Onasch, Konrad. 1962. Einführung in die Konfessionskunde der orthodoxen Kirche. Berlin: Walter de Gruyter \& Co.

Pančenko, Aleksandr M. 1973. Russkaja stichotvornaja kul'tura XVII veka. Leningrad: Izdatel'stvo „Nauka“.

Pavlovskij, Ivan Ja. 1972 [1911]. Russko-nemeckij slovar'. Tret'e, soveršenno pererabotannoe, ispravlennoe i dopolnennoe izdanie, Bd. I-II. Leipzig: Zentral-Antiquariat der Deutschen Demokratischen Republik.

Pelc, Janusz. 1990. Tren. In Stownik literatury staropolskiej. Hrsg. von Teresa Michatowska, 873-877. Wrocław, Warszawa \& Kraków: Zakład Narodowy im. Ossolińskich

Polockij, Simeon. 1999. Vertograd mnogocvětnyj. Bd. II. Hrsg. von Anthony Hippisley \& Lydia I. Sazonova. Köln, Weimar \& Wien: Böhlau.

Polockij, Simeon. 2000. Vertograd mnogocvetnyj. Bd. III. Hrsg. von Anthony Hippisley \& Lidija I. Sazonova. Köln, Weimar \& Wien: Böhlau.

Polockij, Simeon. 2013-2017. Rifmologion. Eine Sammlung höfisch-zeremonieller Gedichte, Bd. II. Hrsg. von Anthony Hippisley, Hans Rothe \& Lydia I. Sazonova. Wien, Köln \& Weimar: Böhlau.

Robinson, Andrej N. 1974. Bor'ba idej v russkoj literature XVII veka. Moskva: Izdatel'stvo „Nauka“.

Sazonova, Lidija I. 2006. Literaturnaja kul'tura Rossii. Rannee Novoe vremja. Moskva: Jazyki slavjanskich kul'tur.

Sazonova, Lidija I. 2013. Rifmologion Simeona Polockogo - kniga pridvorno-ceremonial'noj poėzii. In Simeon Polockij 2013, Rifmologion. Eine Sammlung höfisch-zeremonieller Gedichte, LXXXVII-CLX. Wien, Köln \& Weimar: Böhlau.

Sazonova, Lidija I. 2017. Rukopis' Rifmologiona: paleografičeskoe opisanie. In Simeon Polockij, Rifmologion. Eine Sammlung höfisch-zeremonieller Gedichte, Bd. II. Hrsg. von Anthony Hippisley, Hans Rothe \& Lydia I. Sazonova, XI-XXXVI. Wien, Köln \& Weimar: Böhlau. 
Segebrecht, Wulf. 1977. Das Gelegenheitsgedicht. Ein Beitrag zur Geschichte und Poetik in der deutschen Lyrik. Stuttgart: Metzler.

Slovar' 1992 [1913] - Polnyj pravoslavnyj bogoslovskij ènciklopedičeskij slovar', Bd. I-II. Moskva: Izdatel'stvo P. P. Sojkina.

Sreznevskij, Izmail I. 1893. Materialy dlja slovarja drevnerusskago jazyka, Bd. I. Sanktpeterburg: Tipografija Imperatorskoj akademii nauk.

Strätling, Susanne. 2005. Allegorien der Imagination: Lesbarkeit und Sichtbarkeit im russischen Barock. München: Fink.

Sukina, Ljudmila B. 2011. Čelovek verujuščij v russkoj kul'ture XVI-XVII vekov. Moskva: Rossijskij gosudarstvennyj gumanitarnyj universitet.

Tatarskij, lerofej A. 1886. Simeon Polockij (Ego žizn' i dejatel'nost'). Opyt issledovanija iz istorii prosveščenija i vnutrennej cerkovnoj žizni vo votoruju polovinu XVII veka. Moskva: M. G. Volčaninov.

Thyrêt, Isolde. 2001. Between God and Tsar. Religious Symbolism and the Royal Women of Muscovite Russia. DeKalb/Ill.: Northern Illinois University Press.

Torke, Hans-Joachim. 1986a. Altes Moskau und neues Rußland unter Aleksej Michajlovič nach 1649. In Handbuch der Geschichte Rußlands, Bd. II, 97-122. Stuttgart: Hiersemann.

Torke, Hans-Joachim. 1986b. Der Durchbruch der Neuzeit unter Fedor und Sof'ja 1676-1689. In Handbuch der Geschichte Rußlands, Bd. II, 152-182. Stuttgart: Hiersemann.

Tschižewskij, Dmitrij. 1968. Außerhalb der Schönheit. Außerästhetische Elemente in der Slavischen Barockdichtung. In Die nicht mehr schönen Künste. Grenzphänomene des Ästhetischen. Hrsg. von Hans Robert Jauß, 207-238. München: Fink.

van Ingen, Ferdinand J. 1966. Vanitas und Memento mori in der deutschen Barocklyrik. Groningen: J. B. Wolters.

Vasmer, Max. 1953. Russisches etymologisches Wörterbuch. Bd. I. Heidelberg: Winter.

Vilinbachova, Tatiana. 2002. The Image of Death in the Art of Ancient Russia. In Humana fragilitas. The Themes of Death in Europe from the 13th Century to the 18th Century. Hrsg. von Roberto Tenenti, 251-268. Clusone: Ferrari editrice.

Vovelle, Michel. 1983. La mort et l'occident. De 1300 à nos jours. Paris: Gallimard.

Vroon, Ronald. 2001. K istokam ciklizacii stichotvornych panegirikov v èpochu russkogo barokko. In Tekst. Intertekst. Kul'tura. Sbornik dokladov meždunarodnoj naučnoj konferencii (Moskva, 4-7 aprelja 2001 goda). Hrsg. von V. P. Grigor'ev \& N. A. Fateeva, 155-166. Moskva: Azbukovnik.

Wiegand, Herrmann. 1997. Epicedium. Trauer- und Trostgedicht. In Reallexikon der deutschen Literaturwissenschaft. Hrsg. von Klaus Weimar, Bd. I, 455-457. Berlin \& New York: De Gruyter.

Zabelin, Ivan E. 2001 [1901]. Domašnij byt russkich caric v XVI i XVII st., Bd. II. Moskva: lazyki russkoj kul'tury.

Zen’kovskij, Sergej A. 1970. Russkoe staroobrjadčestvo. Duchovnye dviženija semnadcatogo veka. München: Fink.

Živov, Viktor M. 1996. Jazyk i kul'tura v Rossii XVIII veka. Moskva: Jazyki russkoj kul'tury.

Živov, Viktor M. 2010a. Handling Sin in Eighteenth-Century Russia. In Representing Private Lives of the Enlightenment. Hrsg. von Andrew Kahn, 123-148. Oxford: Voltaire Foundation.

Živov, Viktor M. 2010b. Institutionalized Soteriology in the Western and Eastern Churches. In Slavica Ambrosiana 1: 51-76. 